\section{Aggressive incidents in first-episode psychosis}

\author{
JOHN MILTON, SHAZAD AMIN, SWARAN P. SINGH, GLYNN HARRISON, \\ PETER JONES, TIM CROUDACE, IAN MEDLEY and JOHN BREWIN
}

\section{Background Recent research has reported increased risk of aggressive incidents by individuals with psychotic illness.}

\section{Aims To examine acts of aggression in first-episode psychosis.}

Method Subjects with a first-episode psychosis were ascertained from a defined catchment area (Nottingham, UK) and reassessed at 3 years $(n=166)$ using clinical interview, informants, health care and forensic records.

\section{Results Of the subjects, $9.6 \%$} demonstrated at least one act of serious aggression (defined as weapon use, sexual assault or victim injury) during at least one psychotic episode and 23.5\% demonstrated lesser acts of aggression (defined as all other acts of aggression). For all aggressive subjects (33.1\%), unemployment $(\mathrm{OR}=3.6,95 \% \mathrm{Cl}$.6-8.0), comorbid substance misuse $(\mathrm{OR}=3 . \mathrm{I}, \mathrm{Cl}$ I.I-8.8) and symptoms of overactivity at service contact $(\mathrm{OR}=6.9, \mathrm{Cl}$ 2.7-17.8) had independent effects on risk of aggression.

Conclusions We confirmed some previously reported demographic and clinical associations with aggression in first-episode psychosis but no relationship with specific psychotic symptoms or diagnostic groups was observed.

Declaration of interest Support was received from the National Health Service Executive (Trent Research \& Development).
The renaissance in the psychiatric epidemiology of violence suggests that individuals with mental disorder may be two or three times more likely to behave violently than controls (Brennan et al, 2000). Those diagnosed with psychotic illness can be at higher risk of harming others (Swanson, 1994) and acquiring a criminal conviction for violence (Wessely et al, 1994). Schizophrenia (Tiihonen et al, 1997) and substance misuse disorders (Swanson et al, 1990) have been particularly implicated. Evidence regarding the relationship between specific symptoms and violence is conflicting; some reports link violence by individuals experiencing psychosis with persecutory delusions associated with passivity (so-called 'threatcontrol-override (TCO) syndrome'; Link $\&$ Stueve, 1994), whereas others find no increase in the overall risk of violence due to delusions (Appelbaum et al, 2000). Several UK inquiries into homicides by people with mental illness, usually psychosis (Ritchie et al, 1994), have raised the awareness of risk management (Royal College of Psychiatrists, 1996). Hence, there is considerable interest in identifying factors that are associated with and predict aggressive behaviour towards others by individuals with psychosis.

This study aimed to examine aggressive acts associated with an epidemiologically defined cohort of patients with a firstepisode psychosis presenting to secondary psychiatric services and followed up 3 years later. Our objectives were:

(a) to estimate the frequency and severity of aggression towards others during specified time periods;

(b) to ascertain the characteristics at episode onset associated with subjects demonstrating aggression as compared with non-aggressive subjects, and to confirm previously reported demographic and clinical associations with violence by individuals with psychosis.

\section{METHOD}

\section{Sample}

The sample comprised 168 consecutive patients (aged 16-64 years) with a psychotic illness making first contact with psychiatric services in Nottingham (UK) between 1 June 1992 and 31 May 1994 (from a population of 397148 ). All subjects met the criteria in the Screening Schedule for Psychosis (Jablensky et al, 1992). Descriptions of case ascertainment and demographic characteristics of this cohort (including determination of ethnic origin) have been reported previously (Brewin et al, 1997; Harrison et al, 1997).

\section{Follow-up procedure}

Follow-up assessments took place between June 1995 and May 1997, as close as possible to 3 years after first contact. One hundred and forty-three direct interviews $(86 \%)$ were completed, with the remainder relying on other clinical material. We obtained informed consent to interview subjects, to examine their records and to interview their informal carers.

\section{Assessment variables}

Diagnosis

The diagnostic process is described by Brewin et al (1997). Briefly, symptoms were derived from ratings of the Schedules for Clinical Assessment in Neuropsychiatry (SCAN) interview (World Health Organization, 1994), supplemented by other record sources and informant information. Where direct interview was impossible, other information sources, mainly hospital notes, were rated using the Item Group Checklist (IGC; World Health Organization, 1994), according to SCAN rules. When all data had been collected, meetings were held between fieldworkers and the authors G.H. and I.M. and consensus diagnoses were made using ICD10 (World Health Organization, 1992).

Personality was evaluated using the Personality Assessment Schedule (PAS; Tyrer \& Alexander, 1988) and clinical consensus Axis II diagnoses for ICD-10.

\section{Symptoms}

We re-coded 17 of the items in the IGC into a binary format (presence of a symptom, rating $>1$ ). Items were chosen to reflect symptoms implicated in violent behaviour as best evidence from previous research. 
These items then were divided into three symptom subgroups: psychotic, behaviour and 'threat-control-override' (TCO) (see Appendix). Patients were placed in 'high' or 'low' categories, dichotomised by median scores in each subgroup.

Mode of illness onset (speed of evolution of symptoms) was estimated retrospectively using the Operational Criteria Checklist (OPCRIT; McGuffin et al, 1991), broadly categorised as 'acute' if less than 1 month or 'insidious' if greater than 6 months. The Scale for the Assessment of Negative Symptoms (SANS; Andreasen, 1982) was also administered.

\section{Acts of aggression}

Source of data. Offending behaviour (selfreported violence, previous arrests, convictions and imprisonment for violence) was recorded from the Psychiatric and Personal History Schedule (Jablensky et al, 1992), follow-up assessments, psychiatric, community mental health team and general practitioner records and legal reports where available. Three-year follow-up assessment included questions about the nature and frequency of any aggression; the dates of such episodes were obtained exclusively from records. Not all patients consented to access to official offending data, such as Criminal Records Office information.

'Untoward incident' forms (completed by staff following acts of physical disturbance by in-patients, day or out-patients) were obtained for the study period. These forms also recorded when subjects were absent without leave from in-patient wards.

Definition and classification. Acts of aggression were classified according to severity and timing within an individual's illness episode.

(a) Severity of aggression was classified by adapting the two-point scale from the MacArthur Community Violence Instrument (Steadman et al, 1998). Serious aggression (level 2) was defined as weapon use or threat, sexual assault or any other violence with injury to a victim. Lesser aggression (level 1) included all other acts. We considered that verbal threats, without an accompanying weapon, were likely to be recalled unreliably by subjects or informants and not recorded by staff in every case and therefore were not included. These definitions were adopted a priori because the severity of such behaviour was classified retrospectively.

(b) Timing of aggression was categorised into three periods (see Fig. 1). Illness onset was defined as the date of first change of behaviour that was attributable to illness, and not necessarily the date of first psychotic symptoms. Contact with psychiatric services was defined as the date of first contact with secondary psychiatric services with a psychotic illness. Period B therefore represents the clinical 'best estimate' of the duration of untreated illness (DUI). The end of period C was defined as 3 years (to the nearest month for $95 \%$ of cases) after the date of contact with psychiatric services.

\section{Other variables}

The Mental Illness Needs Index (MINI; Glover et al, 1998) was determined from each subject's postcode and dichotomised into proxy measures of low ( $>110$ ) or high $(<110)$ deprivation scores.

\section{Data analysis}

Demographic and clinical characteristics were reported using proportions, means or medians according to their measurement level (discrete or continuous) and distribution (normal or skewed).

Stepwise logistic regression analyses were used to identify clinical and demographic characteristics associated with aggression. Separate analyses were conducted for all acts of aggression and for serious aggression. For each model, odds ratios with $95 \%$ confidence limits were reported for variables meeting the entry criteria. The 11 independent variables (chosen for their previously reported or hypothesised association with aggression and mental disorder) were age, gender, employment, history of violent convictions, MINI score, diagnosis at first contact, comorbid substance misuse diagnosis, total symptom

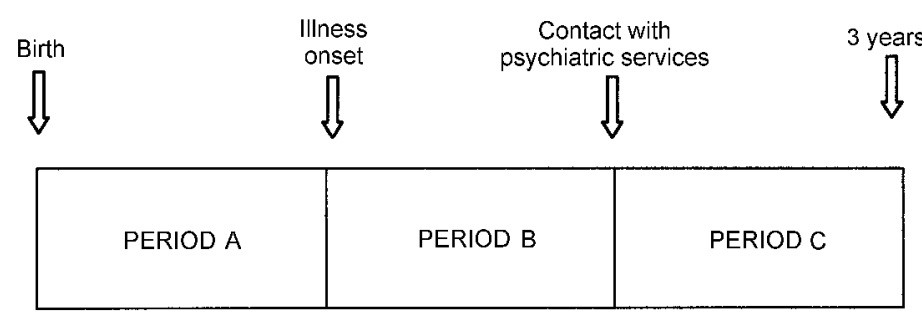

Fig. I Critical time periods. symptom score and TCO score. score, psychotic symptom score, behaviour

\section{RESULTS}

\section{Sample}

Two of the 168 patients who entered the study were excluded: one had an organic psychosis and one withdrew consent for the study. Detailed analysis is therefore presented for 166 subjects. Socio-demographic characteristics and ICD diagnoses have been described for onset (Brewin et al, 1997; Harrison et al, 1997) and follow-up (Amin et al, 1999).

\section{Details of aggressive acts}

Details of timing and severity of all aggressive acts are presented in Fig. 2 and Table 1. A description of victims of all assaults committed 'in episode' is shown in Fig. 3.

Fifty-five $(33.1 \%)$ subjects were responsible for 166 aggressive acts towards others during periods $\mathrm{B}$ and $\mathrm{C}$, some subjects being responsible for several incidents within one time period (e.g. two subjects were responsible for 44 of the aggressive incidents during period C). Of these, 16 subjects $19.6 \%$ of the total sample or $29.1 \%$ of the aggressive group) demonstrated at least one act of serious aggression in periods $\mathrm{B}$ and/or $\mathrm{C}$ and $4(2.4 \%)$ exhibited aggressive behaviour in all time periods. All but one of the 35 subjects who were aggressive during period $\mathrm{C}$ were judged by investigators to be ill at the time of such incidents.

For 20 subjects $(71.4 \%$ of the subjects exhibiting aggression in period $\mathrm{B}$ ) aggression at presentation led directly to psychiatric contact, and in 18 cases the police were involved (10.8\% of the total sample).

Demographic characteristics of subjects exhibiting any aggression towards others while in episode compared with nonaggressive subjects are shown in Table 2 


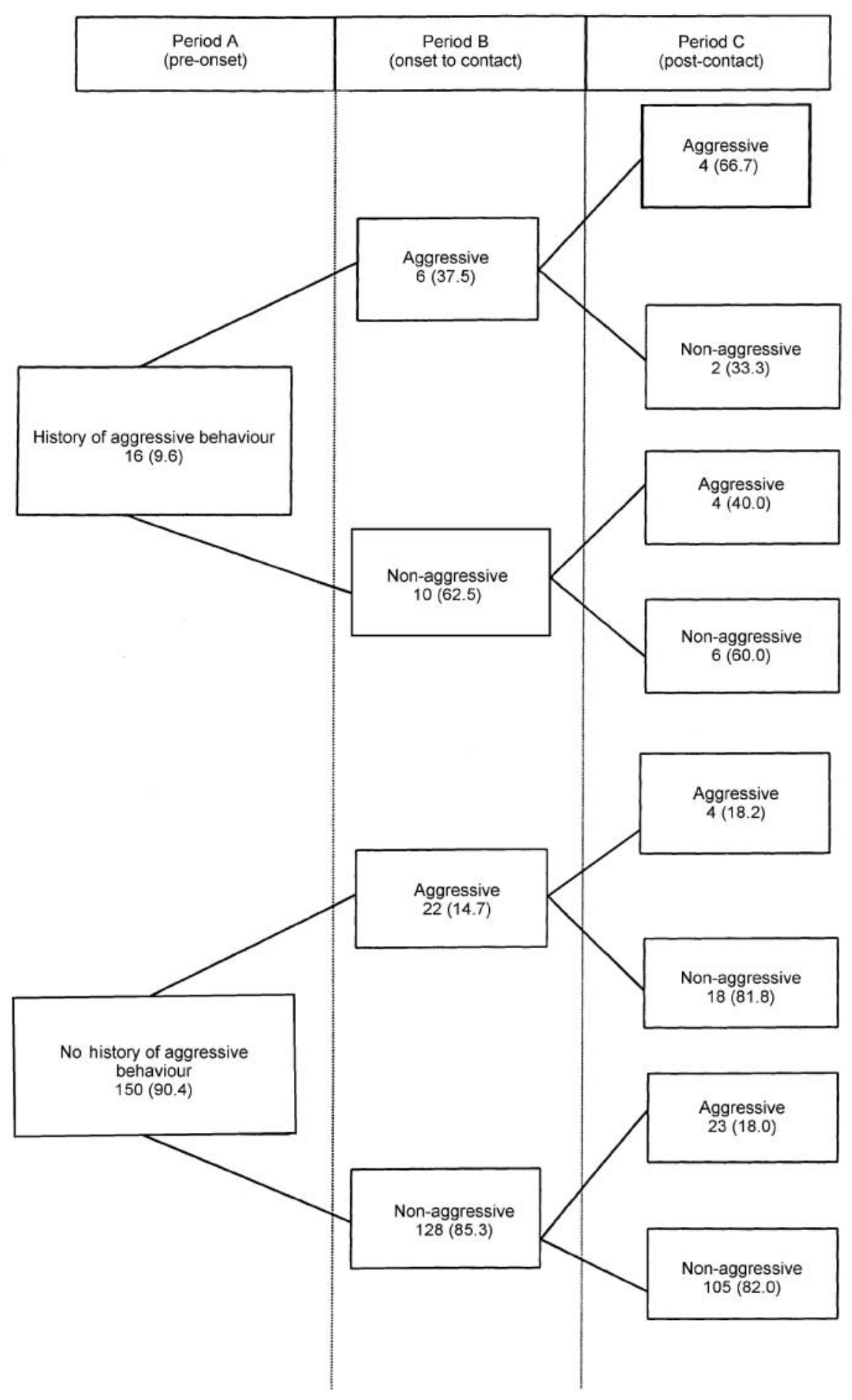

Fig. 2 Subjects exhibiting aggression per time period (number and \% within groups).

and their clinical attributes in Table 3. Other features characteristic of subjects who exhibited aggression after service contact were high rates of absconding from in-patient care $(34.3 \%, \mathrm{OR}=16.6,95 \% \mathrm{CI}$ 4.9-55.9) and increased compulsory admissions over the following 3 years (mean number of sections $=2.2$ and s.d. $=1.5 v$. 0.11 and 0.32 for non-aggressive subjects; $t=-2.4, P=0.017$ ).
For the $29.1 \%$ of aggressive subjects who exhibited serious aggression while ill, a comparison is shown in Table 4 with subjects exhibiting less serious aggression (only positive statistical or relevant associations are shown).

Other than the characteristics shown in Table 4, demographic or clinical features failed to discriminate between lesser and serious aggression. Although more subjects committing serious aggression while ill but before contact had a slow mode of illness onset compared with those committing less serious aggression during the same period $(6 / 8 v .6 / 20, \mathrm{OR}=7.0,95 \%$ CI $1.1-45.2$, $P<0.05)$, their DUI was not significantly longer (median 554 days $v$. 128 days, Mann-Whitney $U=48.0, P=0.10)$.

\section{Symptoms at baseline}

Psychotic symptoms such as delusions, hallucinations and passivity phenomena were common at service contact in both aggressive and non-aggressive groups with no statistically significant differences. For example, persecutory delusions were noted in $71.2 \%$ of non-aggressive subjects and in $83.3 \%$ of subjects who exhibited an aggressive act, with $19.8 \%$ of non-aggressive subjects describing delusions of passivity compared with $12.7 \%$ of aggressive subjects. A summary of IGC symptom group findings is shown in Table 3.

Comparisons of positive scores on individual item groups $(I G)$ from the IGC, recorded at service contact, between subjects who were or were not aggressive after service contact (period C) showed that the aggressive group were significantly more likely to exhibit 'overactivity' (IG19: $\mathrm{OR}=2.2$, 95\% CI 1.1-4.5), 'emotional turmoil' (IG31: OR=2.9, 95\% CI 1.4-5.6), 'socially embarrassing behaviour' (IG34: $\mathrm{OR}=4.0,95 \%$ CI 1.7-9.7) and 'problems in non-verbal communication' (IG37: $\mathrm{OR}=2.5, \quad 95 \%$ CI 1.1-6.0). Subjects exhibiting aggression during period B were also distinguished by symptoms relating to 'overactivity' (IG19: OR=2.8, 95\% CI 1.2-6.5), 'emotional turmoil' (IG31: $\mathrm{OR}=4.1,95 \%$ CI 1.7-9.5), 'socially embarrassing behaviour' (IG34: OR=3.2, 95\% CI 1.2-8.0) and 'problems in non-verbal communication' (IG37: OR=3.1, 95\% CI 1.3-7.6) as well as 'self-neglect' (IG38: $\mathrm{OR}=3.5,95 \%$ CI $1.3-9.5$ ), but were less likely to exhibit delusions of persecution (IG30: OR=2.5, 95\% CI 1.1-5.0), delusions of reference $(I G 29: \mathrm{OR}=2.5,95 \%$ CI 1.25-5.0) or bizarre delusions (IG27: $\mathrm{OR}=2.5$, 95\% CI 1.1-5.0).

Seriously aggressive subjects were also characterised by 'overactivity' (IG19: OR= $3.4,95 \%$ CI 1.2-9.8) and 'deficits in nonverbal communication' (IG37: $\mathrm{OR}=5.5$, 95\% CI 1.9-16.2) and were less likely to exhibit bizarre delusions (IG27: $\mathrm{OR}=5.0$ 95\% CI 1.4-10.0). There was no significant difference between total SANS scores for 
Table I Number of subjects exhibiting aggressive behaviour by type, timing and severity $(n=166)$

\begin{tabular}{|c|c|c|c|c|c|c|c|}
\hline \multirow[t]{2}{*}{$\begin{array}{l}\text { Type of } \\
\text { aggressive act }{ }^{1}\end{array}$} & \multicolumn{2}{|c|}{$\begin{array}{c}\text { Period A } \\
\text { (pre-illness) }\end{array}$} & \multicolumn{2}{|c|}{$\begin{array}{c}\text { Period B } \\
\text { (onset to contact) }\end{array}$} & \multicolumn{2}{|c|}{$\begin{array}{c}\text { Period C } \\
\text { (post-contact) }\end{array}$} & \multirow[t]{2}{*}{$\begin{array}{c}\text { Total no. of } \\
\text { subjects }\end{array}$} \\
\hline & $\begin{array}{c}\text { No. of } \\
\text { subjects }\end{array}$ & $\begin{array}{c}\text { No. of } \\
\text { episodes }\end{array}$ & $\begin{array}{l}\text { No. of } \\
\text { subjects }\end{array}$ & $\begin{array}{c}\text { No. of } \\
\text { episodes }\end{array}$ & $\begin{array}{c}\text { No. of } \\
\text { subjects }\end{array}$ & $\begin{array}{c}\text { No. of } \\
\text { episodes }\end{array}$ & \\
\hline Total & 16 & 20 & 28 & 42 & 35 & 104 & 61 \\
\hline Serious & 10 & 14 & 8 & 15 & 8 & 10 & 21 \\
\hline Less serious & 6 & 6 & 20 & 27 & 27 & 94 & 40 \\
\hline
\end{tabular}

I. For each period, if subjects have recorded both serious and less serious acts of aggression, the more serious act is rated preferentially.

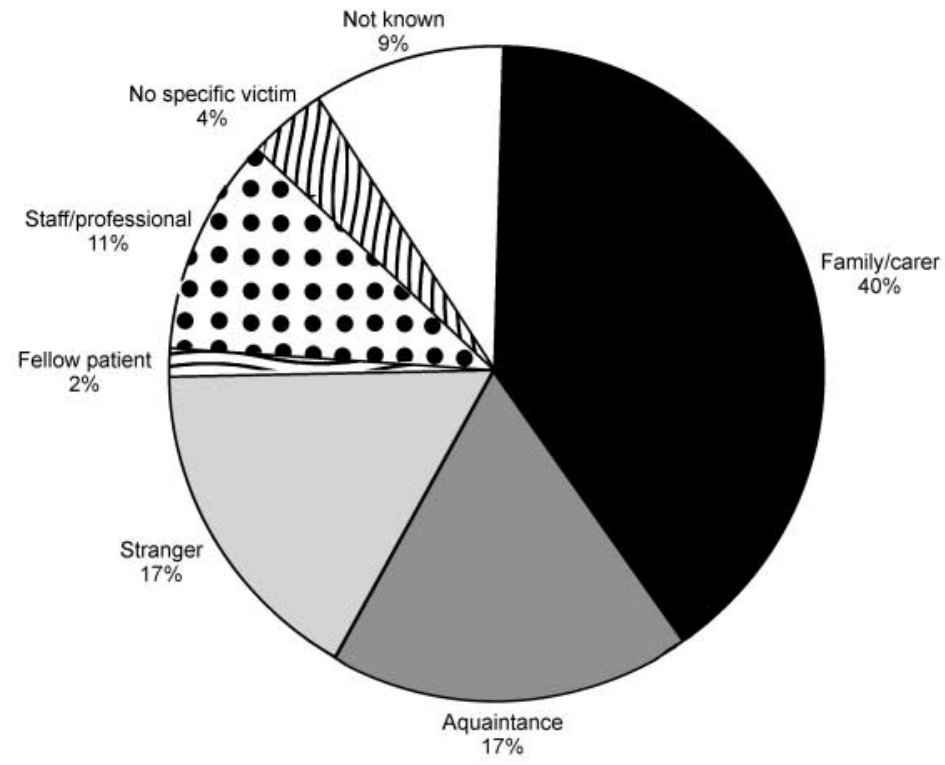

Fig. 3 Victims of all assaults by subjects in episode.

aggressive and non-aggressive subjects $(t=-0.37$, d.f. $=147, P=0.71)$.

\section{Substance misuse}

No data on substance misuse were available for $14(8.4 \%)$ cases. Thirteen $(8.6 \%$ of 152$)$ subjects had primary substance-related psychoses (ICD-10 F1x) and 15 (9.9\%) other subjects had ICD-10 comorbid substance misuse and psychotic disorders, mostly illicit drugs $(93.3 \%)$ rather than alcohol. Comparisons between substance misuse variables for aggressive and nonaggressive subjects are shown in Table 3 .

\section{Personality}

The PAS data were unavailable for 74 (44\%) subjects and therefore were not evaluated. Consensus F60 personality disorders were recorded for six subjects: one schizoid, one emotionally unstable and four dissocial personality disorders. No statistical associations were found between those with comorbid personality disorder and aggression.

\section{Multivariate analyses}

Two multiple logistic regression models were used to assess the risk of subjects exhibiting either any aggression or serious aggression while in episode. Of the 11 independent variables, age, gender, diagnosis at first contact, history of violent convictions, MINI score, total symptom severity score and psychotic symptom score did not meet the entry criteria. A high behaviour symptom group score $(\mathrm{OR}=6.9$, 95\% CI 2.7-17.8), comorbid substance misuse diagnosis $(\mathrm{OR}=3.1,95 \%$ CI 1.1 $8.8)$ and being unemployed $(\mathrm{OR}=3.6,95 \%$ CI 1.6-8.0) all had an independent effect on the risk of exhibiting any aggression. A high TCO score had an independent effect on reduced risk of any aggression (OR=2.8, 95\% CI 1.3-6.3).

For the model of serious aggression while in episode, a history of convictions for violence $(\mathrm{OR}=12.6,95 \%$ CI 3.5-45.1) was the only independent variable to meet the entry criteria other than high TCO score, which was negatively associated with risk $(\mathrm{OR}=4.1$, 95\% CI 1.2-14.7).

\section{DISCUSSION}

This study utilised an epidemiologically defined cohort of patients diagnosed with first-episode psychosis presenting to secondary psychiatric services to examine the relationship between first-episode psychosis and aggression.

\section{Methodological strengths and limitations}

Criticisms of previous studies examining the relationship between violence and mental disorder have been described in the MacArthur Violence Risk Assessment (MVRA) Study (Steadman et al, 1994).

Briefly, there are three types of problem: use of 'static' predictor variables (usually socio-demographic variables) rather than dynamic (symptom profile or timing of violent behaviour) variables; narrowly defined patient samples - in-patients (Raja et al, 1997), 'high risk' discharges from secure psychiatric or prison facilities (Rice \& Harris, 1995) or single diagnostic groups (Humphreys et al, 1992) and data-sets restricted to individuals arrested or readmitted to hospital (Wessely et al, 1994; Tiihonen $e t$ al, 1997). This study therefore sought to use a representative first-episode community-based sample, a broad diagnostic range of psychotic disorders and multiple data sources.

Our findings have several limitations. First, and of greatest hindrance to conclusions about prevalence, is the absence of a non-psychosis comparison group representative of the population from which our subjects were taken.

Second, the overall study was not designed primarily to obtain data on aggression or offending. Because difficulties with confidentiality and consent were encountered in accessing statutory criminological data, an incomplete criminological data-set probably reduced the prevalence of reported offending. Although the use of multiple data sources (e.g. informant interviews or psychiatric records) has been 
Table 2 Demographic and diagnostic characteristics of subjects aggressive during period B (pre-contact) and period C (post-contact) compared with non-aggressive subject group

\begin{tabular}{|c|c|c|c|c|c|c|}
\hline \multirow[t]{3}{*}{ Variable } & \multirow{3}{*}{$\begin{array}{c}\begin{array}{c}\text { Non-aggressive group } \\
(n=\mathrm{III})\end{array} \\
\% \text { of } \mathrm{I} 66 \text { subjects }\end{array}$} & \multicolumn{5}{|c|}{$\begin{array}{c}\text { Aggression during illness group } \\
\text { (some subjects are included during both periods } B \text { and } C \text { ) }\end{array}$} \\
\hline & & \multicolumn{2}{|c|}{$\begin{array}{l}\text { Pre-contact (period B) } \\
\qquad(n=28)\end{array}$} & \multicolumn{2}{|c|}{$\begin{array}{l}\text { Post-contact (period C) } \\
\qquad(n=35)\end{array}$} & \multirow{2}{*}{$\begin{array}{c}\text { Total } n=55 \\
\text { (aggression } v \text {. non-aggression) } \\
\text { OR }(95 \% \mathrm{Cl})\end{array}$} \\
\hline & & $\%$ & OR $(95 \% \mathrm{Cl})$ & $\%$ & $(95 \% \mathrm{Cl})$ & \\
\hline \multicolumn{7}{|l|}{ Gender } \\
\hline Male & 53.2 & 78.6 & $3.2^{*}(1.2-8.6)$ & 68.6 & $1.9(0.9-4.3)$ & $2.1 *(1.1-4.3)$ \\
\hline \multicolumn{7}{|l|}{ Ethnicity } \\
\hline White & 74.8 & 67.9 & $0.7 \quad(0.3-1.8)$ & 68.6 & $0.7(0.3-1.7)$ & $0.8(0.4-I .5)$ \\
\hline African-Caribbean & I7.I & 21.4 & $1.3 \quad(0.5-3.7)$ & 28.6 & $1.9 \quad(0.8-4.7)$ & $1.6(0.8-3.6)$ \\
\hline Other & 7.2 & 10.7 & $1.5(0.4-6.2)$ & 2.9 & $0.4(0.5-3.1)$ & $0.7 \quad(0.2-2.9)$ \\
\hline Unemployed & 46.4 & 75.0 & $3.5^{* *}(1.4-8.8)$ & 80.0 & $4.6 * *(1.9-11.5)$ & $3.7^{* *}(1.8-7.7)$ \\
\hline Living alone & 28.9 & 21.4 & $0.6 \quad(0.3-1.8)$ & $3 \mathrm{I} .4$ & I.I (0.5-2.6) & $0.8 \quad(0.4-1.6)$ \\
\hline Age (mean, s.d.)' & $32.9(12.3)$ & & $26.5(9.1)^{* *}$ & & $29.0 \quad(5.9)^{* *}$ & $26.6(7.9)^{* *}$ \\
\hline \multicolumn{7}{|l|}{ Diagnosis } \\
\hline Schizophrenia & 34.2 & 35.7 & $1.2(0.4-2.5)$ & 37.1 & I.I $\quad(0.5-2.5)$ & $1.2(0.6-2.3)$ \\
\hline Other psychosis & 65.8 & 64.3 & $0.9(0.4-2.2)$ & 62.9 & $0.8 \quad(0.4-1.9)$ & $0.8 \quad(0.4-1.6)$ \\
\hline Any compulsory admissions & 32.4 & 67.9 & $4.4 * *(1.8-10.7)$ & 85.7 & $12.5^{* *}(4.5-35.0)$ & $6.7 * *(3.2-14.1)$ \\
\hline Any convictions & 9.0 & 32.1 & $4.8^{* *}(1.7-13.3)$ & 30.3 & $4.3^{* *}(1.6-11.8)$ & $4.4^{* *}(1.8-10.5)$ \\
\hline Previous violent convictions & 4.5 & 25.0 & $7.1 * *(2.0-24.4)$ & 22.9 & $6.8^{* *}(2.0-23.5)$ & $5.6 * *(1.8-16.9)$ \\
\hline Any aggression & 5.4 & 25.0 & $5.8^{* *}(1.8-19.1)$ & 26.5 & $6.3^{* *}(2.1-19.3)$ & $5.0 * *(1.8-14.2)$ \\
\hline Prior imprisonment & 5.4 & 21.4 & $4.8 *(1.4-16.2)$ & 22.9 & $5.2^{* *}(1.7-16.2)$ & $4.4^{* *}(1.5-12.6)$ \\
\hline
\end{tabular}

$* P<0.05 ; * * P<0.01$ (Fisher's exact test).

I. $t$-Test. Period B: $t=3.1$; period C: $t=4.4$; total: $t=4.0$.

Table 3 Clinical variables for subjects aggressive during period B (pre-contact) and period C (post-contact) individually compared with non-aggressive subject group

\begin{tabular}{|c|c|c|c|c|c|c|}
\hline \multirow[t]{3}{*}{ Variable } & \multirow{3}{*}{$\begin{array}{c}\text { Non-aggressive } \\
\text { group }(n=I I I) \\
\%\end{array}$} & \multicolumn{5}{|c|}{$\begin{array}{c}\text { Aggression during illness group } \\
\text { (some subjects were aggressive during both periods B and C) }\end{array}$} \\
\hline & & \multicolumn{2}{|c|}{$\begin{array}{l}\text { Pre-contact (period B) } \\
\qquad(n=28)\end{array}$} & \multicolumn{2}{|c|}{$\begin{array}{l}\text { Post-contact (period C) } \\
\qquad(n=35)\end{array}$} & \multirow{2}{*}{$\begin{array}{c}\text { Total }(n=55) \\
\text { (non-aggressive } v . \\
\text { aggressive) OR }(95 \% \mathrm{Cl})\end{array}$} \\
\hline & & $\%$ & OR $(95 \% \mathrm{Cl})$ & $\%$ & OR $(95 \% \mathrm{Cl})$ & \\
\hline \multicolumn{7}{|l|}{ IIIness variables } \\
\hline \multicolumn{7}{|l|}{ Mode of illness onset } \\
\hline Insidious ( $>6$ months) & 27.0 & 42.9 & $2.0(0.9-4.8)$ & 22.9 & $0.8 \quad(0.3-2.0)$ & $1.2(0.6-2.5)$ \\
\hline Single illness episode & 36.8 & 28.6 & $0.7 \quad(0.3-1.7)$ & I7.1 & $0.4 *(0.1-0.9)$ & $0.6(0.3-1.2)$ \\
\hline Duration of untreated illness (median, days) ${ }^{\prime}$ & 75 & 136 & & 68 & & 85 \\
\hline \multicolumn{7}{|l|}{ Substance misuse variables } \\
\hline $\begin{array}{l}\text { ICD-I0 drug-related psychosis at onset } \\
\qquad(\mathrm{FI} x), n=13\end{array}$ & 9.0 & 7.4 & $0.8 \quad(0.2-4.0)$ & 6.1 & $0.7 \quad(0.1-3.2)$ & $0.8 \quad(0.2-2.9)$ \\
\hline $\begin{array}{l}\text { Fl } x \text { additional ICD-10 diagnosis ('dual } \\
\text { diagnosis'), } n=15\end{array}$ & 4.0 & II.I & $3.0 \quad(0.6-14.3)$ & 27.3 & $9.0 * *(2.6-31.7)$ & $6.4^{* *}(1.9-21.4)$ \\
\hline \multicolumn{7}{|l|}{ Symptom variables (from the IGC) } \\
\hline High IG total symptom score & 34.2 & 57.1 & $2.6 *(1.1-6.0)$ & 45.7 & $1.6(0.8-3.5)$ & $1.9(0.96-3.6)$ \\
\hline High IG behaviour score & 54.1 & 85.7 & $5.1^{* *}(1.7-15.7)$ & 82.9 & $4.1 * *(1.6-10.7)$ & $3.6^{* *}(1.8-8.3)$ \\
\hline High IG psychotic score & 54.1 & 32.1 & $0.4 \quad(0.2-1.0)$ & 48.6 & $0.8 \quad(0.4-\mid .7)$ & $0.7 \quad(0.3-1.3)$ \\
\hline High IG TCO score & 63.1 & 32.1 & $0.3^{* *}(0.1-0.7)$ & 54.3 & $0.7 \quad(0.3-1.5)$ & $0.5^{*}(0.3-0.9)$ \\
\hline
\end{tabular}

IG, item group; IGC, Item Group Checklist; TCO, threat-control-override.

$* P<0.05 ; * * P<0.01$

I. Mann-Whitney $U$-test. Period B: $U=1232$; period C: $U=1815$; total: $U=2958$. 
Table 4 Comparison between serious and less serious aggression groups while ill

\begin{tabular}{|c|c|c|c|}
\hline Variable & $\begin{array}{c}\text { Serious } \\
\text { aggression to } \\
\text { others } \\
(n=16)\end{array}$ & $\begin{array}{l}\text { Less serious } \\
\text { aggression to } \\
\text { others } \\
(n=39)\end{array}$ & Odds ratio \\
\hline \multicolumn{4}{|l|}{ Demographic and aggression variables } \\
\hline Age (mean, s.d.)' & 28.9 (II.I) & $28.8(6.0)$ & \\
\hline Any pre-illness aggression, $\%(n=10)$ & 31.3 & 12.8 & $3.1 \quad(0.8-12.7)$ \\
\hline Any serious pre-illness aggression, $\%(n=7)$ & 25.0 & 7.7 & $4.0 \quad(0.8-20.5)$ \\
\hline Any pre-illness convictions, $\%(n=16 / 53)$ & 60.0 & 18.4 & $6.6 * *(1.8-24.8)$ \\
\hline Any pre-illness violent convictions, $\%(n=I \mathrm{I} / 53)$ & 46.7 & 10.5 & $7.4^{* *}(1.7-31.7)$ \\
\hline \multicolumn{4}{|l|}{ Clinical variables } \\
\hline $\begin{array}{l}\text { Mode of illness onset: insidious } \\
\text { ( }>6 \text { months), } \%(n=17)\end{array}$ & 56.3 & 20.5 & $5.0 *(1.4-17.5)$ \\
\hline \multicolumn{4}{|l|}{ Duration of untreated illness, days } \\
\hline Mean (s.d.) $)^{2}$ & $613(954)$ & $227(620)$ & \\
\hline Median & 226 & 76 & \\
\hline High IG symptom score, $\%(n=27)$ & 56.3 & 46.2 & $1.5(0.5-4.8)$ \\
\hline High IG behaviour score, $\%(n=45)$ & 68.8 & 87.2 & $0.3(0.1-1.3)$ \\
\hline High IG psychotic score, $\%(n=24)$ & 25.0 & 51.3 & $0.3(0.1-1.2)$ \\
\hline High IG TCO score, $\%(n=25)$ & 25.0 & 53.8 & $0.3 \quad(0.1-1.0)$ \\
\hline
\end{tabular}

$* P<0.05 ; * * P<0.01$

I. $t$-Test: $t=-1.4$.

2. Mann-Whitney $U$-test: $U=187.5 *$

shown to increase significantly the reported prevalence of violence (Steadman et al, 1998), our findings still have limitations. For example, even in prospective studies such as the MVRA Study, subject attrition can be high, leading to restrictions in collection and analysis of violence-related data. Sources such as psychiatric case notes have been shown to underestimate convictions for violence among mentally disordered offenders by almost $50 \%$ in a UK sample of homicide perpetrators (Shaw et al, 1999). Additionally, use of 'untoward incident' records may bias the reporting of aggressive incidents after service contact and in in-patient settings: either overreporting due to individuals' increased exposure to the scrutiny of health care staff or underreporting because aggression may be accepted by staff as symptomatic of mental disorder.

Third, modifications made to the IGC to allow comparison of symptoms across the whole cohort have yet to be validated as a means of assessing symptom clusters. However, the SCAN interview is widely used and good reliability between raters was demonstrated for this study (Brewin et al, 1997). We chose particular item groups and then adopted sub-scales based upon established empirical evidence for their association with violence. This approach has face validity although it could be criticised for focusing on particular target symptoms, thus biasing findings towards certain symptoms at the expense of other previously unreported but potentially important symptom areas.

Lastly, because the study was not conceived to ascertain clinical and contextual variables at the precise time of all aggressive acts, it was not always possible to elicit retrospectively (either from patients or informants) the precise motives after illness onset, although most attributed aggression after service contact to illness. Also, only those patients whose pre-contact aggression led to immediate admission received a SCAN interview temporally related to the incident. For the remaining subjects, we drew conclusions from SCAN interviews shortly after service contact about the relationship between psychopathology at service contact and at times of aggression. It could be argued also that the differentiation of illness episode into specific time periods is arbitrary, particularly when change in behaviour (rather than emergence of first psychotic symptom) was the criterion used. This could be relevant if different risk factors for aggression prevail at difference time periods of illness.

\section{Type and frequency of aggression towards others}

Approximately one-third of subjects exhibited aggressive behaviour during periods $B$ and $C$ and one-sixth after the onset of symptoms but prior to service contact. Comparisons with other UK samples are limited by diagnostic heterogeneity. However, the proportion of subjects with schizophrenia exhibiting aggression prior to contact $(10 / 54$ or $18.5 \%)$ is similar to another UK study (21\%) (Humphreys et al, 1992) but less than that described for developed countries $(31.5 \%)$ in the World Health Organization's study on the Determinants of Outcome of Severe Mental Disorders (DOSMD; Volavka et al, 1997).

Aggressive acts were more common after service contact. Despite this, only four $(2.4 \%)$ subjects demonstrated aggression in all the time periods studied (i.e. premorbidly and after illness). Serious aggression was more prevalent before onset of illness and diminished in frequency in proportion to less serious aggression after onset and contact with secondary services. However, the overall number of subjects committing lesser acts of aggression increased. Although this may relate in part to reporting bias after service contact, further analysis of the timing of violent events relative to symptoms and illness course is required.

Our findings regarding the victims of aggression by subjects with psychosis are in broad agreement with the MVRA Study (Steadman et al, 1998), where family and acquaintances form the majority of victims. Further study of the location, social context and social networks of subjects with psychosis in relation to aggression is needed.

\section{Diagnosis, symptoms and violence}

Excluding substance misuse (ICD-10 F1x) comorbidity, diagnostic group alone did not confer any special risk of aggression, regardless of aggression type or severity. This contrasts with other studies of serious offending, which report an increased risk for schizophrenia of both homicide (Eronen et al, 1996) and violent conviction (Tiihonen et al, 1997).

In agreement with recent findings from the MVRA Study (Appelbaum et al, 2000), we did not confirm previous reports linking specific psychotic symptoms and aggression. We found that although delusions, hallucinations and passivity phenomena were common, they did not specifically 
distinguish subjects who were aggressive, either in isolation or as the TCO syndrome. We also confirmed Appelbaum et al's (2000) finding that higher TCO scores at baseline assessment were inversely related to the risk of further aggression, serious or otherwise. Such findings, relating to an inception rather than a discharge cohort, may add weight to Appelbaum et al's conclusions that "presumed risk of violence associated with delusions per se does not justify hospitalisation of a patient, in the absence of other indicators of violence risk or of other reasons for inpatient treatment".

Symptoms that were associated with aggression and present at service contact were apparent in two areas. First, behavioural symptoms, such as overactivity and emotional turmoil, had large and independent effects on risk of aggression. This has some precedence in the symptoms of excitement found in acute-onset disorders during the DOSMD study (Volavka et al, 1997). Second, symptoms related to aspects of negative symptoms and deficits in communication appeared to be characteristic of subjects, mainly younger men with insidious illness onset, who exhibited serious aggression towards others and specifically after illness onset and before service contact. However, higher global ratings of negative symptoms were not characteristic of these subjects.

In addition to insidious illness onset and past history of convictions for violence, subjects with psychosis who demonstrated serious aggression also had longer periods of untreated illness. Duration of untreated illness has attracted attention as an important factor associated with outcome across a number of domains (McGorry et al, 2000). Although the association with aggression could provide opportunities for reducing the DUI in order to diminish indirectly the risk of aggression, the relationship may be an artefact. Because the length of period B varied considerably (from a few days to over 10 years), it is possible that the connection between the DUI and aggression represents a longer period at risk.

Only a small number of subjects received any Axis II diagnosis. Our findings are likely to represent an underestimation of personality disorder, owing to the absence of interview- or informant-based personality data for all subjects.

\section{Substance misuse and violence}

Previous research has identified a relationship between substance misuse and violence, either alone or in combination with major mental disorder (Swanson et al, 1990; Tiihonen et al, 1997; Steadman et al, 1998). In a UK sample, Scott et al (1998) reported that individuals with comorbid psychosis and substance misuse are more likely to exhibit hostile behaviour and assaults than those with psychosis alone.

We confirmed that ICD-10 F1 $x$ diagnostic comorbidity, but not primary drug-related psychosis, at onset had an independent effect on the risk of subjects exhibiting aggression during a psychotic episode. Individuals with drug-related comorbidity were nine times more likely to exhibit aggression after service contact. Whether this represents reporting bias and how such individuals' substance misuse covaries with their psychotic disorder over time requires further study. Comorbid alcohol misuse was not a significant association for violence, as reported in the DOSMD study (Volavka et al, 1997).

\section{ACKNOWLEDGEMENTS}

We thank Mrs Rosemary Kwiecinski for her help with the assessments and administration of the database and Professor Conor Duggan for his comments on a draft of the paper.

\section{APPENDIX}

\section{Scores of Symptom Severity}

The following 17 items (including all psychotic symptom items) are taken from the first 41 item groups of the Item Group Checklist (World Health Organization, 1994) as being the most relevant to violent behaviour (based upon previous reported research).

\section{Total symptom severity rating}

(maximum score $=17$, low $=0-5$, high $=6+$ )

IG03 Autonomic anxiety and panic

IGI3 Depressive delusions and hallucinations

IGI5 Heightened subjective functioning

IGI6 Rapid subjective tempo

IGI8 Expansive delusions and hallucinations

IGI9 Overactivity

IG2I Non-specific auditory hallucinations

IG23 Non-specific psychotic

IG24 Non-affective auditory hallucinations

IG25 Experience of disordered form of thought

IG26 Delusions of control

IG27 Bizarre delusions and interpretations

IG28 Miscellaneous delusions

IG29 Delusions of reference

IG30 Delusions of persecution

IG3I Emotional turmoil, etc.

IG34 Socially embarrassing behaviour

\section{Psychotic symptom subgroup}

(maximum score $=\| 1$, low $=0-4$, high $=5+$ )

IGI3 Depressive delusions and hallucinations

IGI8 Expansive delusions and hallucinations

IG2I Non-specific auditory hallucinations

IG23 Non-specific psychotic

IG24 Non-affective auditory hallucinations

IG25 Experience of disordered form of thought

IG26 Delusions of control

IG27 Bizarre delusions and interpretations

IG28 Miscellaneous delusions

IG29 Delusions of reference

IG30 Delusions of persecution

\section{Behaviour symptom subgroup}

(maximum score $=6$, low $=0$, high $=1+$ )

IG03 Autonomic anxiety and panic

IGI5 Heightened subjective functioning

IGI6 Rapid subjective tempo

IGI9 Overactivity

IG3I Emotional turmoil, etc.

IG34 Socially embarrassing behaviour

Threat-control-override (TCO) symptom subgroup

( maximum score $=6$, low $=0-2$, high $=3+$ )

IG25 Experience of disordered form of thought

IG26 Delusions of control

IG27 Bizarre delusions and interpretations

IG28 Miscellaneous delusions

IG29 Delusions of reference

IG30 Delusions of persecution

\section{REFERENCES}

Amin, S., Singh, S. P., Brewin, J., et al (1999) Diagnostic stability of first-episode psychosis. Comparison of ICD-10 and DSM-III-R systems. British Journal of Psychiatry, 175, 537-543.

Andreasen, N. (1982) The Scale for the Assessment of Negative Symptoms (SANS). lowa City, IA: The University of lowa.

Appelbaum, P., Robbins, P. \& Monaham, J. (2000) Violence and delusions: data from the MacArthur Violence Risk Assessment Study. American Journal of Psychiatry, 157, 566-572.

Brennan, P., Mednick, S. \& Hodgins, S. (2000) Major mental disorders and criminal violence in a Danish birth cohort. Archives of General Psychiatry, 57, 494-500.

Brewin, J., Cantwell, R., Dalkin, T., et al (1997)

Incidence of schizophrenia in Nottingham. A comparison of two cohorts, 1978-1980 and 1992-1994. British Journal of Psychiatry, I7I, 140-144.

Eronen, M., Tiihonen, J. \& Hakola, P. (1996) Schizophrenia and homicidal behaviour. Schizophrenia Bulletin, 22, 83-89.

Glover, G., Robin, E., Emami, J., et al (1998) A needs index for mental health care. Social Psychiatry and Psychiatric Epidemiology, 33, 89-96.

Harrison, G., Glazebrook, C., Brewin, J., et al (1997) Increased incidence of psychotic disorders in AfricanCaribbean migrants to the UK. Psychological Medicine, 27, 799-806. 
Humphreys, M. S., Johnstone, E. C., MacMillan, J. F., et al (1992) Dangerous behaviour preceding first admissions for schizophrenia. British Journal of Psychiatry 16I, 50|-505.

Jablensky, A., Sartorius, N., Ernberg, G., et al (1992) Schizophrenia: Manifestations, Incidence and Course in Different Cultures. A World Health Organization Ten Country Study. Psychological Medicine Monograph Supplement 20. Cambridge: Cambridge University Press.

Link, B. \& Stueve, A. (1994) Psychotic symptoms and the violent/illegal behaviour of mental patients compared to community controls. In Violence and Mental Disorder: Developments in Risk Assessment (eds J. Monahan \& H. Steadman), pp. 135-161. Chicago, IL: University of Chicago Press.

\section{McGorry, P. D., Krstev, H. \& Harrigan, S. (2000)} Early detection and treatment delay: implications for outcome in early psychosis. Current Opinion in Psychiatry, 13, 37-43.

\section{McGuffin, P., Farmer, A. \& Harvey, I. (1991) A} polydiagnostic application of operational criteria in psychotic illness: development and reliability of the OPCRIT system. Archives of General Psychiatry, 48, 764-770.

Raja, M., Azzoni, A. \& Lubich, L. (1997) Aggressive and violent behaviour in a population of psychiatric inpatients. Social Psychiatry and Psychiatric Epidemiology, 32, 428-434.

Rice, M. \& Harris, G. (1995) Psychopathy, schizophrenia, alcohol abuse and violent recidivism. International Journal of Law Psychiatry, 18, 333-342.

Ritchie, J., Dick, D. \& Lingham, R. (1994) Report of the Inquiry into the Care and Treatment of Christopher Clunis. London: HMSO.

Royal College of Psychiatrists (1996) Assessment and Clinical Management of Risk of Harm to Other People. (Council Report CR53). London: Royal College of Psychiatrists.

Scott, H., Johnson, S., Menezes, P., et al (1998) Substance misuse and risk of aggression and offending among the severely mentally ill. British Journal of Psychiatry, I72, 345-350.

Shaw, J., Appleby, L., Amos, T., et al (1999) Mental disorder and clinical care in people convicted of homicide: national clinical survey. British Medical Journal 318, 1240-1244

Steadman, H., Monahan, J., Appelbaum, P., et al (1994) Designing a new generation of risk assessment research. In Violence and Mental Disorder: Developments in Risk Assessment (eds J. Monahan \& H. Steadman), pp. 297-318. Chicago, IL: University of Chicago Press.

_ , Mulvey, E., Monahan, J., et al (1998) Violence by people discharged from acute psychiatric inpatient facilities and by others in the same neighborhoods. Archives of General Psychiatry, 55, 393-40I.

Swanson, J. (1994) Mental disorder, substance abuse and community violence: an epidemiological approach. In Violence and Mental Disorder: Developments in

\section{CLINICAL IMPLICATIONS}

- Within a community-based first-episode psychosis cohort $33.1 \%$ of the subjects exhibited aggression, predominantly minor acts, towards family members.

Comorbid substance misuse and overexcited behaviour (but not psychotic symptoms) were independently associated with subjects perpetrating aggressive acts.

- A history of convictions for violence was characteristic of the $9.6 \%$ of subjects committing acts of serious aggression.

\section{LIMITATIONS}

The absence of a comparison group of individuals without psychosis with similar socio-demographic characteristics limits the empirical utility of our findings.

- Underreporting of aggressive or offending behaviour may have occurred, owing to incomplete statutory criminological data.

- The use of symptom subgroups has yet to be validated as a means of assessing symptom clusters in relation to aggressive acts.

IOHN MILTON, MRCPsych, East Midlands Centre for Forensic Mental Health, Leicester; SHAZAD AMIN MRCPsych, Moorside, Trafford General Hospital, Manchester; SWARAN P. SINGH, MRCPsych, Division of Psychiatry, University of Nottingham, Nottingham; GLYNN HARRISON, FRCPsych, Division of Psychiatry, University of Bristol, Bristol; PETER JONES, MRCPsych, TIM CROUDACE, PhD, IAN MEDLEY, MRCPsych, JOHN BREWIN, MRCPsych, Division of Psychiatry, University of Nottingham, Nottingham, UK

Correspondence: Dr John Milton, East Midlands Centre for Forensic Mental Health, Arnold Lodge, Cordelia Close, Leicester LE5 OLE, UK. Tel: 0116225 6060; Fax: 0116225 606I ; e-mail: John.Milton@arnoldl.cnhc-tr.trent.nhs.uk

(First received 22 October 1999, final revision 7 December 2000, accepted II December 2000)

Risk Assessment (eds J. Monahan \& H. Steadman), Pp. I0I-136. Chicago, IL: University of Chicago Press.

—, Holzer, C., Ganju, V., et al (1990) Violence and psychiatric disorder in the community: evidence from the epidemiologic catchment area surveys. Hospital Community Psychiatry, 41, 761-770

Tiihonen, J., Isohanni, M., Rasanen, P., et al (1997) Specific major mental disorders and criminality: a 26 year prospective study of the 1966 Northern Finland birth cohort. American Journal of Psychiatry, 154, 840-845.

Tyrer, P. \& Alexander, J. (1988) Personality Assessment Schedule. In Personality Disorders (ed. P. Tyrer), pp. 43-62. London: Wright.
Volavka, J., Laska, E., Baker, S., et al (1997) History of violent behaviour and schizophrenia in different cultures. Analyses based on the WHO study on Determinants of Outcome of Severe Mental Disorders. British Journal of Psychiatry, I7I, 9-14.

Wessely, S., Castle, D., Douglas, A., et al (1994) The criminal careers of incident cases of schizophrenia. Psychological Medicine, 24, 483-502.

World Health Organization (1992) Tenth Revision of the International Classification of Diseases and Related Health Problems (ICD-I0). Geneva: WHO.

(1994) SCAN: Schedules for Clinical Assessment in Neuropsychiatry (Version 2). Geneva: WHO. 